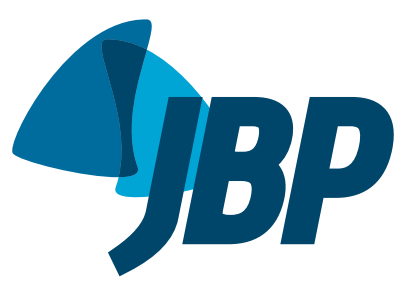

1. Unidade de Circulação Pulmonar Disciplina de Pneumologia, Instituto do Coração, Hospital das Clínicas, Faculdade de Medicina, Universidade de São Paulo, São Paulo (SP) Brasil.

Submitted: 2 March 2016 Accepted: 22 March 2016

Study carried out in the Unidade de Circulação Pulmonar, Disciplina de Pneumologia, Instituto do Coração, Hospital das Clínicas, Faculdade de Medicina, Universidade de São Paulo, São Paulo (SP) Brasi.

\title{
New anticoagulants for the treatment of venous thromboembolism
}

\author{
Caio Julio Cesar dos Santos Fernandes ${ }^{1}$, José Leonidas Alves Júnior ${ }^{1}$, \\ Francisca Gavilanes ${ }^{1}$, Luis Felipe Prada', Luciana Kato Morinaga', \\ Rogerio Souza'
}

\begin{abstract}
Worldwide, venous thromboembolism (VTE) is among the leading causes of death from cardiovascular disease, surpassed only by acute myocardial infarction and stroke. The spectrum of VTE presentations ranges, by degree of severity, from deep vein thrombosis to acute pulmonary thromboembolism. Treatment is based on full anticoagulation of the patients. For many decades, it has been known that anticoagulation directly affects the mortality associated with VTE. Until the beginning of this century, anticoagulant therapy was based on the use of unfractionated or low-molecular-weight heparin and vitamin $\mathrm{K}$ antagonists, warfarin in particular. Over the past decades, new classes of anticoagulants have been developed, such as factor $\mathrm{Xa}$ inhibitors and direct thrombin inhibitors, which significantly changed the therapeutic arsenal against VTE, due to their efficacy and safety when compared with the conventional treatment. The focus of this review was on evaluating the role of these new anticoagulants in this clinical context.

Keywords: Blood coagulation; Venous thromboembolismltherapy; Venous thromboembolisml prevention and control.
\end{abstract}

\section{INTRODUCTION}

Worldwide, venous thromboembolism (VTE) is the third leading cause of cardiovascular mortality, surpassed only by myocardial infarction and stroke, ${ }^{(1,2)}$ and affects patients in various populations, including the pediatric population. ${ }^{(3,4)}$ Deep vein thrombosis (DVT) is the most prevalent presentation of VTE, and its most severe form is acute pulmonary thromboembolism (PTE). ${ }^{(5)}$ In both situations, the main treatment consists of full anticoagulation and is aimed at reducing VTE recurrence. Studies conducted in the 1960 s systematically showed that anticoagulants reduce mortality when administered to patients with VTE in general ${ }^{(6)}$ and to those with PTE in particular. ${ }^{(7)}$

Despite the fact that the anticoagulation cascade (Figure 1) has long been known, the choice of drugs that could actually influence it was initially limited. Although traditional anticoagulants were effective in the treatment of VTE, ${ }^{(8)}$ practical difficulties in their management led to the development of new drugs for this purpose. Two groups of oral anticoagulants-factor Xa inhibitors (rivaroxaban, apixaban, and edoxaban) and direct thrombin inhibitors (dabigatran)-have recently been made available, and the evidence that justifies their use in VTE will be discussed below.

\section{CLASSIC ANTICOAGULATION AND WARFARIN}

The American College of Chest Physicians (ACCP) recommends, for teaching purposes, that VTE treatment be divided into three periods: an initial period, from diagnosis to the seventh day; a long-term period; and an extended period. In the initial period, an intravenous anticoagulant (unfractionated heparin) or a subcutaneous anticoagulant (enoxaparin, nadroparin, dalteparin, tinzaparin, or fondaparinux) is classically used. Subsequently, in the long-term period, intravenous or subcutaneous therapy is switched to oral therapy, which should be maintained for at least 3 months. The most extensively studied drugs in this condition are vitamin $\mathrm{K}$ antagonists, of which warfarin is the most prominent representative. Warfarin produces its effect by interfering with the cyclic interconversion of vitamin $\mathrm{K}$ and vitamin $\mathrm{K} 2$,3-epoxide, thus blocking vitamin $\mathrm{K}$-dependent coagulation factor synthesis (factors II, VII, IX, and X). Therefore, the anticoagulant effect of warfarin does not occur until the factors already present in the circulation are metabolized, a process that typically takes 36-72 h. During the first days of warfarin treatment, prolongation of the prothrombin time reflects only the loss of factor VII (the half-life of which is 5-7 h), and this does not represent adequate anticoagulation, given that the intrinsic clotting pathway remains functional. Efficient blockade of this pathway takes about 5 days (hence the ACCP recommendation to maintain intravenous or subcutaneous anticoagulant therapy during this period). After 3 months, at the end of the long-term period, the need to continue anticoagulant therapy should be assessed, and, that being the case, this extended period should last as long as the benefits of anticoagulation (prevention of VTE recurrence) surpass its potential harms (risk of bleeding). ${ }^{(9)}$

Warfarin treatment in the long-term and extended periods has proven to be effective in preventing VTE

Correspondence to:

Caio Julio Cesar dos Santos Fernandes. Avenida Dr. Enéas de Carvalho Aguiar, 44, $5^{\circ}$ andar, Instituto do Coração, Hospital das Clínicas, Faculdade de Medicina,

Universidade de São Paulo, CEP 05403-900, São Paulo, SP, Brasil.

Tel.: 5511 2661-5695. E-mail: cjcfernandes@gmail.com

Financial support: None. 
Intrinsic Pathway

Extrinsic Pathway

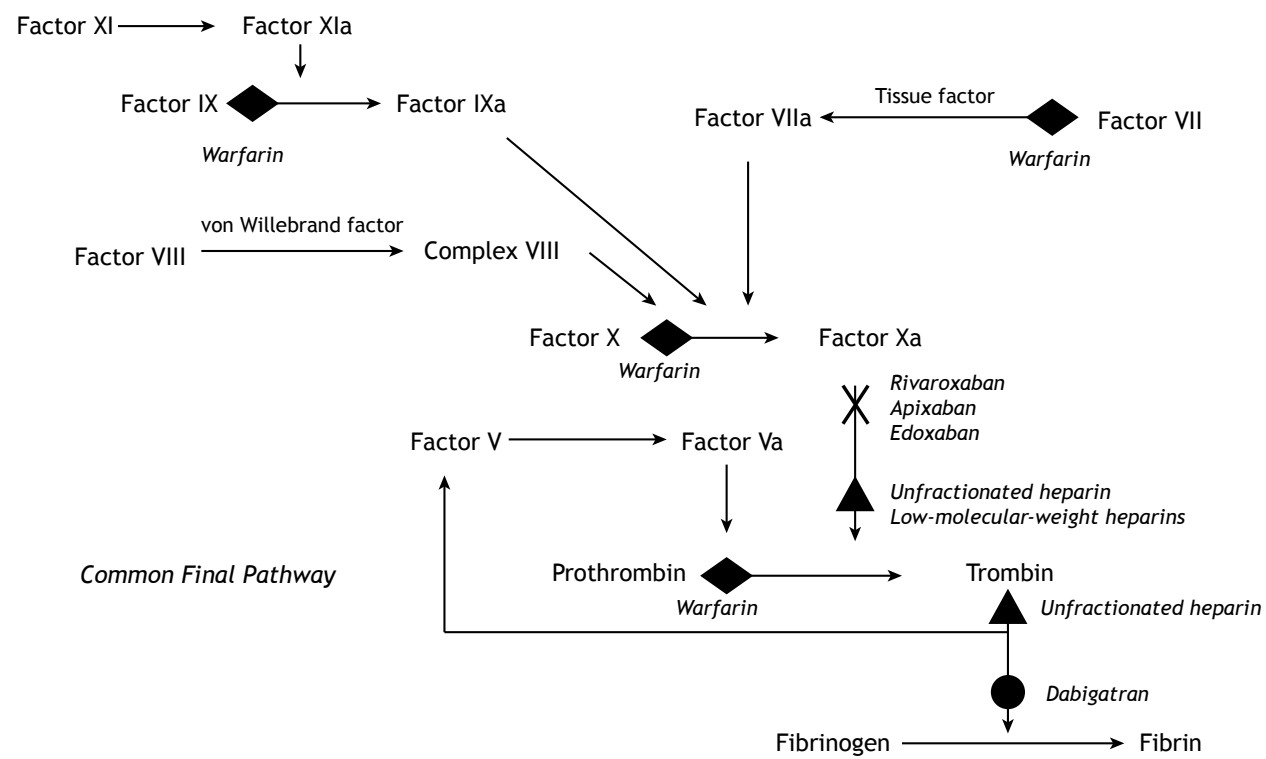

Figure 1. Anticoagulation cascade with the sites of action of the anticoagulants.

recurrence. ${ }^{(10,11)}$ A meta-analysis of 8 randomized studies involving 2,994 patients with PTE showed that patients who were treated with warfarin for an extended period were less likely to have recurrence $(\mathrm{OR}=0.18 ; 95 \% \mathrm{CI}: 0.13-0.26)$ than were those in whom warfarin was discontinued after 1-4 months of treatment. ${ }^{(12)}$

Despite being effective, the use of warfarin has a number of drawbacks. ${ }^{(13)}$ Given the narrow therapeutic range of warfarin, there is a need for constant monitoring of its action, which is not always feasible. Recent data from the first cohort of the Global Anticoagulant Registry in the Field (GARFIELD) studyshow that, among 6,047 patients on vitamin $\mathrm{K}$ antagonists, monitoring of drug action via the international normalized ratio (INR) was recorded for only 3,952 patients, and only 1,660 had a therapeutic level that met the current recommendation, with a time in therapeutic range (TTR) above $60 \% .^{(14)}$ This is particularly true in Brazil. The Randomized Evaluation of Long-Term Anticoagulation Therapy (RE-LY) study showed that, whereas worldwide the mean TTR of the 6,000 patients on warfarin was $64 \%$, it was only $54 \%$ among those in Brazil $^{(15)}$; that is, even in a situation that is closer to optimal than is clinical practice, within an international research protocol, the reality is that maintaining a warfarin-treated patient within an appropriate therapeutic range is costly and complex.

Another difficulty with the use of warfarin is the issue of safety. As with any anticoagulant, there is the fear of bleeding as a side effect of its use. ${ }^{(16)}$ An argument in favor of the use of warfarin is the theoretical possibility of monitoring the intensity of anticoagulation, via the INR (prothrombin time test results). Therefore, if a patient had an INR within the therapeutic range (between 2 and 3), the risk of bleeding would be minimal or nonexistent. However, evidence from the most recent studies shows that, whereas patients with a TTR above $60 \%$ have a lower rate of VTE recurrence, the same is not true for the bleeding rates. ${ }^{(17)}$ In other words, keeping INR levels stable and within the recommended range does not reduce the risk of bleeding; it affects only the risk of recurrence.

Other drawbacks of the use of warfarin include multiple food and drug interactions, impairment of patient quality of life, and difficulty of management for physicians, which ultimately implies suboptimal therapy, given the fear of adverse events. ${ }^{(13)}$

Based on the problems experienced in the use of vitamin $\mathrm{K}$ antagonists, it is possible to devise some theoretical characteristics of an optimal anticoagulant: oral administration; a rapid onset of action; a short half-life; a wide therapeutic margin; therapeutic effect prediction with a fixed dose or based on body weight; few drug or food interactions; monitoring not required (but possible if desired); well-established pharmacokinetics in the presence of hepatic or renal failure; easily reversible effects in the presence of bleeding; and cost-effectiveness. These principles have led, in the last decade, to the emergence of new anticoagulants (Table 1) with properties aimed at filling such gaps, thereby improving outpatient anticoagulation in patients with VTE, which, in the last 50 years, has remained at the same level and has been based on the use of vitamin $\mathrm{K}$ antagonists.

\section{DABIGATRAN}

Dabigatran is a direct thrombin (or factor II) inhibitor. It is an oral drug that is administered in prodrug form, 
with no interaction with food. Its onset of action occurs within $2 \mathrm{~h}$ of administration, and its half-life is $12-17$ h. Because $80 \%$ of dabigatran is excreted by the kidneys, its use is contraindicated in patients with a creatinine clearance $<30 \mathrm{~mL} / \mathrm{min}$. Its bioavailability is $3-7 \%$ of the administered dose. Dabigatran causes clinically relevant dyspepsia in $5-10 \%$ of cases, and concomitant proton pump inhibitor use reduces dabigatran absorption by $20-30 \%$. ${ }^{(18)}$

Dabigatran was the first new anticoagulant to be systematically evaluated for the treatment of VTE. In one study, (19) 2,539 patients with acute VTE (70\% with DVT, $20 \%$ with PTE, and $10 \%$ with both) were randomized, after being treated with full-dose enoxaparin for 5 days, to receive either dabigatran $150 \mathrm{mg}$ every $12 \mathrm{~h}$ or warfarin. After 6 months of treatment, dabigatran proved to be as effective as warfarin in preventing VTE recurrence ( $2.4 \%$ vs. $2.1 \%$; $\mathrm{p}<0.001$ for non-inferiority). Dabigatran proved to be superior to the conventional treatment in terms of "any bleeding" (16.1\% vs. $21.9 \%$; 95\% CI: 0.59-0.85) and to be equivalent to it in terms of "major bleeding" (1.6\% vs. $1.9 \% ; 95 \% \mathrm{CI}: 0.45-1.48$ ). Of the patients on dabigatran, $9 \%$ had to discontinue treatment because of adverse events, compared with $6.8 \%$ of the patients on warfarin $(p=0.05) .^{(19)}$

The initial data on dabigatran were quite encouraging. Dabigatran proved to be as effective as and potentially safer than the conventional treatment of VTE, if not in the initial period then at least in the long-term period. Extended treatment of VTE with dabigatran was evaluated in two randomized, double-blind trials. ${ }^{(20)}$ In those trials, patients who had been on full anticoagulation for at least 3 months were randomized to receive dabigatran, warfarin, or placebo for 18 months, on average. In the dabigatran vs. warfarin study, 26 of a total of 1,430 patients in the dabigatran group $(1.8 \%)$ had VTE recurrence, compared with 18 of 1,426 patients in the warfarin group (1.3\%; $p$ $=0.01$ for non-inferiority). Major bleeding occurred at similar rates $(0.9 \%$ in the dabigatran group vs. $1.8 \%$ in the warfarin group; $95 \% \mathrm{CI}: 0.27-1.02$ ). In terms of "all types of bleeding", dabigatran proved to be superior to warfarin (relative risk $[R R]=0.54$; 95\% CI: $0.41-0.71$ ). Of note in that study is that patients in the dabigatran group had a higher rate of acute coronary syndrome events than did those in the warfarin group ( $0.9 \%$ vs. $0.2 \% ; p=0.02)$. In the dabigatran vs. placebo study, VTE recurred in 3 of 681 patients $(0.4 \%)$ in the dabigatran group and in 37 of 681 patients $(5.6 \%)$ in the placebo group ( $p<0.001$ ). Major bleeding occurred in $0.3 \%$ of the patients in the dabigatran group and in none of those in the placebo group. "Any bleeding" occurred in 5.3\% of the patients in the dabigatran group and in $1.8 \%$ of those in the placebo group $(\mathrm{RR}=2.92 ; 95 \% \mathrm{CI}$ : $1.52-5.60)$. There were no differences in the rate of acute coronary syndrome events. ${ }^{(20)}$

Although the finding related to coronary events in long-term studies was striking, as was some difficulty in profiling adverse events, especially adverse gastrointestinal events, dabigatran proved to be a viable, effective, and potentially safer alternative to warfarin for the treatment of VTE, both in the long-term period and in the extended period. Caution is recommended if dabigatran is used in patients with a history of

Table 1. Studies of new oral anticoagulants for the treatment of venous thromboembolism.

\begin{tabular}{|c|c|c|c|c|c|c|}
\hline Drug & Mechanism & Study & Doses & $\begin{array}{c}\text { Treatment } \\
\text { duration, } \\
\text { months }\end{array}$ & $\begin{array}{l}\text { Efficacy (fatal } \\
\text { VTE recurrence; } \\
\text { non-inferiority)) }\end{array}$ & $\begin{array}{c}\text { Safety } \\
\text { (MB or MRB) }\end{array}$ \\
\hline Dabigatran & Thrombin & $\begin{array}{l}\text { Schulman } \\
\text { et al. }{ }^{(19)}\end{array}$ & $\begin{array}{l}\text { Enoxaparin/ } \\
\text { dabigatran } 150 \mathrm{mg} \\
\text { every } 12 \mathrm{~h}\end{array}$ & 6 & $\begin{array}{l}\text { Dabigatran }(2.4 \%) \\
\text { vs. warfarin }(2.1 \%)\end{array}$ & $\begin{array}{l}\text { MB: dabigatran } \\
(1.6 \%) \text { vs. } \\
\text { warfarin }(1.9 \%)\end{array}$ \\
\hline Dabigatran & inhibitor & $\begin{array}{l}\text { Schulman } \\
\text { et al. }{ }^{(47)}\end{array}$ & $\begin{array}{l}\text { Enoxaparin/ } \\
\text { dabigatran } 150 \mathrm{mg} \\
\text { every } 12 \mathrm{~h}\end{array}$ & 6 & $\begin{array}{l}\text { Dabigatran }(2.3 \%) \\
\text { vs. warfarin }(2.2 \%)\end{array}$ & $\begin{array}{l}\text { MB: dabigatran } \\
(0.3 \%) \text { vs. } \\
\text { warfarin }(0.0 \%)\end{array}$ \\
\hline Rivaroxaban & & $\begin{array}{l}\text { EINSTEIN } \\
\text { Investigators } \\
\text { et al. }{ }^{(21)}\end{array}$ & $\begin{array}{l}\text { Rivaroxaban } 15 \mathrm{mg} \\
\text { every } 12 \mathrm{~h} \text { for } 3 \\
\text { weeks; } 20 \mathrm{mg} / \text { day }\end{array}$ & 3,6, or 12 & $\begin{array}{l}\text { Rivaroxaban }(2.1 \%) \\
\text { vs. warfarin }(3.0 \%)\end{array}$ & $\begin{array}{l}\text { MRB: } \\
\text { rivaroxaban } \\
(8.1 \%) \text { vs. } \\
\text { warfarin }(8.1 \%)\end{array}$ \\
\hline Rivaroxaban & $\begin{array}{l}\text { Factor Xa } \\
\text { inhibitor }\end{array}$ & $\begin{array}{l}\text { EINSTEIN } \\
\text { Investigators } \\
\text { et al. (22) }\end{array}$ & $\begin{array}{l}\text { Rivaroxaban } 15 \mathrm{mg} \\
\text { every } 12 \mathrm{~h} \text { for } 3 \\
\text { weeks; } 20 \mathrm{mg} / \text { day }\end{array}$ & 3,6, or 12 & $\begin{array}{l}\text { Rivaroxaban }(2.1 \%) \\
\text { vs. warfarin }(1.8 \%)\end{array}$ & $\begin{array}{l}\text { MRB: } \\
\text { rivaroxaban } \\
(10.3 \%) \text { vs. } \\
\text { warfarin } \\
(11.4 \%)\end{array}$ \\
\hline Apixaban & $\begin{array}{l}\text { Factor } \mathrm{Xa} \\
\text { inhibitor }\end{array}$ & $\begin{array}{l}\text { Agnelli } \\
\text { et al. }{ }^{(23,24)}\end{array}$ & $\begin{array}{l}\text { Apixaban } 10 \mathrm{mg} \\
\text { every } 12 \mathrm{~h} \text { for } 7 \\
\text { days; } 5 \mathrm{mg} \text { every } \\
12 \mathrm{~h}\end{array}$ & 6 & $\begin{array}{l}\text { Apixaban }(2.3 \%) \text { vs. } \\
\text { warfarin }(2.7 \%)\end{array}$ & $\begin{array}{l}\text { MB: apixaban } \\
(0.6 \%) \text { vs. } \\
\text { warfarin }(1.8 \%)\end{array}$ \\
\hline Edoxaban & $\begin{array}{l}\text { Factor Xa } \\
\text { inhibitor }\end{array}$ & $\begin{array}{l}\text { Hokusai-VTE } \\
\text { Investigators } \\
\text { et al. }{ }^{(25)}\end{array}$ & $\begin{array}{l}\text { Low-molecular- } \\
\text { weight heparin for } \\
5 \text { days; edoxaban } \\
60 \text { mg/day }\end{array}$ & $3-12$ & $\begin{array}{l}\text { Edoxaban }(3.2 \%) \text { vs. } \\
\text { warfarin }(3.5 \%)\end{array}$ & $\begin{array}{l}\text { MRB: edoxaban } \\
(8.5 \%) \text { vs. } \\
\text { warfarin } \\
(10.3 \%)\end{array}$ \\
\hline
\end{tabular}

VTE: venous thromboembolism; MB: major bleeding; and MRB: major/relevant bleeding. 
coronary artery disease, dyspepsia, or renal failure. The recommended dose for VTE treatment with dabigatran, following a 5-day course of parenteral or subcutaneous anticoagulation, is $150 \mathrm{mg}$ every $12 \mathrm{~h}$. If the estimated creatinine clearance is $<30 \mathrm{~mL} / \mathrm{min}$, dabigatran is contraindicated. Patients with a creatinine clearance of $30-50 \mathrm{~mL} / \mathrm{min}$ and $>80$ years of age should use a $110-\mathrm{mg}$ dose every $12 \mathrm{~h}$, as should those who are at high risk of bleeding. A $110-\mathrm{mg}$ dose every $12 \mathrm{~h}$ can also be considered for patients $>80$ years of age even if they have a creatinine clearance $>50 \mathrm{~mL} / \mathrm{min}$.

\section{RIVAROXABAN}

Rivaroxaban is a factor Xa antagonist. It is an oral drug that is administered in its active form. Its onset of action occurs within 2-3 $\mathrm{h}$ of administration. The bioavailability of rivaroxaban is increased when it is administered with food (66\% without food and $100 \%$ with food); it is therefore recommended that it be administered with food. No significant dyspeptic effects or reduction in rivaroxaban absorption are observed with concomitant use of proton pump inhibitors. Approximately $35 \%$ of rivaroxaban is excreted by the kidneys; its half-life is $5-9 \mathrm{~h}$ in young individuals and $11-13 \mathrm{~h}$ in elderly individuals. There is interaction with drugs that are metabolized by (hepatic) cytochrome CYP3A4, such as ketoconazole, ritonavir, clarithromycin, and erythromycin. ${ }^{(18)}$

The first randomized study evaluating rivaroxaban in patients with VTE was published in 2010. The EINSTEIN program produced significant advances in this field in two aspects: patients with $\mathrm{DVT}^{(21)}$ and patients with PTE ${ }^{(22)}$ were evaluated separately, the latter being known to be patients with different severity of disease and different prognoses; and the protocols of the randomized trials were the first to propose replacing the intravenous or subcutaneous anticoagulation of the initial phase after the diagnosis of VTE directly with an oral drug, inaugurating the single drug approach. Therefore, the proposal was to treat the episode of VTE (either DVT or PTE) with a single oral drug from diagnosis through the long-term period (up to 3 months) and the extended period.

In the study published in 2010, called EINSTEIN-DVT, (21) 3,449 patients with DVT were randomized to receive either rivaroxaban ( $15 \mathrm{mg}$ every $12 \mathrm{~h}$ for 3 weeks, followed by $20 \mathrm{mg}$ every $24 \mathrm{~h}$ for 3,6 , or 12 months after the diagnosis of acute VTE) or enoxaparin $(1 \mathrm{mg} / \mathrm{kg}$ every $12 \mathrm{~h}$ for at least 5 days, followed by warfarin for the same period). Rivaroxaban proved to be as effective as the conventional treatment in terms of the rate of VTE recurrence $(2.1 \%$ vs. $3.0 \%$; $\mathrm{p}<0.001$ for non-inferiority). The bleeding rate was identical in the two groups $(8.1 \%)$. In addition, the same study included a group called EINSTEIN-Extension, in which, after being treated for VTE for at least 3 months, 1,196 patients were randomized to receive either rivaroxaban or placebo for 12 months. There was VTE recurrence in $1.3 \%$ of the patients who received rivaroxaban, compared with $7.1 \%$ of the patients in the placebo group ( $p<0.001$ ), and $0.7 \%$ of the patients in the rivaroxaban group had nonfatal major bleeding, compared with none in the placebo group $(p=0.11)$. $^{(21)}$

In 2012, the EINSTEIN-PE (Pulmonary Embolism) study was published. ${ }^{(22)}$ In that study, 4,832 patients with acute PTE were randomized to receive either rivaroxaban (15 mg every $12 \mathrm{~h}$ for 3 weeks, followed by $20 \mathrm{mg} /$ day for 3,6 , or 12 months after the diagnosis of acute PTE) or enoxaparin ( $1 \mathrm{mg} / \mathrm{kg}$ every $12 \mathrm{~h}$ for at least 5 days, followed by warfarin for the same period). Rivaroxaban proved to be as effective as the conventional treatment with warfarin in terms of the rate of VTE recurrence ( $2.1 \%$ vs. $1.8 \% ; p=0.003$ for non-inferiority). The bleeding rate in the rivaroxaban and conventional treatment groups was $10.3 \%$ and $11.4 \%$, respectively $(p=0.23)$. However, rivaroxaban had a quite favorable result in terms of "major bleeding" when compared with warfarin: $1.1 \%$ vs. $2.2 \%$ (RR = $0.49 ; 95 \% \mathrm{CI}: 0.31-0.79 ; p=0.003)$. This benefit in terms of major bleeding occurred early in therapy and is therefore not due only to the presence of warfarin in the conventional treatment. Even in the initial period of enoxaparin therapy, rivaroxaban had a better safety profile than did the conventional treatment. It is worth emphasizing that patients who had hemodynamic instability or required thrombolytic therapy were not included in that study. ${ }^{(22)}$

The studies comprising the EINSTEIN program showed that rivaroxaban was as effective as the conventional treatment (enoxaparin in the acute phase and warfarin in the long-term and extended periods) in the treatment of acute VTE, providing significant benefits in the rate of major bleeding. Therefore, it became possible to administer a single drug, from the time the diagnosis is made, for the treatment of both DVT and PTE, with similar efficacy to and with potentially greater safety than that of the conventional treatment.

For the treatment of VTE, rivaroxaban should be used at a dose of $15 \mathrm{mg}$ every $12 \mathrm{~h}$ for 3 weeks. Thereafter, for the long-term and extended treatment periods, a dose of $20 \mathrm{mg} /$ day is recommended. During these periods, if the patient has a creatinine clearance of $15-50 \mathrm{~mL} / \mathrm{min}$ or is $>75$ years of age, the recommended dose is 15 $\mathrm{mg} /$ day. For patients with a creatinine clearance $<15$ $\mathrm{mL} / \mathrm{min}$, the use of rivaroxaban in not recommended. The convenient dosing schedule (a single daily dose) is a factor to be considered, because it can influence patient adherence to the treatment, improving its results. However, it is important to emphasize to patients that strict adherence to rivaroxaban therapy is necessary, given that missing even a single dose is sufficient to reverse its anticoagulant effect, leaving patients unprotected and therefore susceptible to having another VTE event.

\section{APIXABAN}

Apixaban is a factor $\mathrm{Xa}$ antagonist. It is an oral drug that is administered in its active form. Its onset of action 
occurs within $3 \mathrm{~h}$ of administration. The bioavailability of apixaban is $50 \%$ and does not depend on food. No significant dyspeptic effects or reduction in apixaban absorption are observed with concomitant use of proton pump inhibitors. Approximately $27 \%$ of apixaban is excreted by the kidneys, and its half-life is $12 \mathrm{~h}$. There is mild interaction with drugs that are metabolized by (hepatic) cytochrome CYP3A4. ${ }^{(18)}$

In 2013, the results of the Apixaban for the initial Management of PuLmonary embolism and deep-vein thrombosis as fIrst-line therapY (AMPLIFY) trial were published. ${ }^{(23)}$ In that trial, 5,395 patients with acute VTE (65\% with DVT, $25 \%$ with PTE; and $10 \%$ with both) were randomized to receive either apixaban (10 mg every $12 \mathrm{~h}$ for 7 days, followed by $5 \mathrm{mg}$ every $12 \mathrm{~h}$ for 6 months); or conventional anticoagulant therapy-subcutaneous enoxaparin followed by warfarin. Again the choice was to use a single drug, from the time the diagnosis of VTE was made. Apixaban was as effective as the conventional treatment in terms of VTE recurrence (2.3\% vs. $2.7 \%$; $p<0.001$ for non-inferiority). Apixaban had a better safety profile, with a rate of major bleeding of $0.6 \%$, compared with $1.8 \%$ for the conventional treatment $(R R=0.31 ; 95 \%$ CI: 0.17-0.55; $p<0.001$ ).

Another study, the AMPLIFY-Extension trial, was published in 2013. ${ }^{(24)}$ In that study, 2,486 patients with VTE who had completed 6 to 12 months of treatment with anticoagulants were randomized to receive apixaban $2.5 \mathrm{mg}$ every $12 \mathrm{~h}$, apixaban $5 \mathrm{mg}$ every 12 $h$, or placebo (all of which were administered for 12 months). The rate of VTE recurrence was $8.8 \%$ in the placebo group, $1.7 \%$ in the apixaban $2.5 \mathrm{mg}$ group, and $1.7 \%$ in the apixaban $5 \mathrm{mg}$ group ( $\mathrm{p}<0.001$ for both comparisons with the placebo group). The safety results reported in that study were also quite significant: the rates of major bleeding were $0.5 \%, 0.2 \%$, and $0.1 \%$, respectively, in the placebo, apixaban $2.5 \mathrm{mg}$, and apixaban $5 \mathrm{mg}$ groups, whereas the rates of minor bleeding were $2.3 \%, 3.0 \%$, and $4.2 \%$.

Studies based on the AMPLIFY trials reported that apixaban has a good efficacy profile and superior efficacy when compared with the conventional treatment, being another drug that can be used as an anticoagulant in the initial phase of the treatment of VTE. In addition, full-dose and prophylactic dose apixaban was shown to have an excellent safety profile in the extended treatment period, preventing late VTE recurrence without increasing the bleeding rates.

The dosing schedule of apixaban for VTE treatment is $10 \mathrm{mg}$ every $12 \mathrm{~h}$ for 7 days. Thereafter, a dose of $5 \mathrm{mg}$ every $12 \mathrm{~h}$ is used for 6 months (as per the AMPLIFY algorithm). If the patient has two of these three characteristics-age $>80$ years, weight $<60 \mathrm{~kg}$, and serum creatinine $<1.5 \mathrm{mg} / \mathrm{dL}$-the dose should be reduced to $2.5 \mathrm{mg}$ every $12 \mathrm{~h}$ after the first week of treatment with the full dose. After the 6 months of treatment, during the extended period, the dose used as prophylaxis against VTE recurrence is 2.5 mg every $12 \mathrm{~h}$.

\section{EDOXABAN}

Edoxaban is a factor Xa antagonist. It is an oral drug that is administered in its active form. The bioavailability of edoxaban is $62 \%$, and its absorption is increased by $6-22 \%$ when it is administered with food. However, there is no recommendation that edoxaban be administered concomitantly with food. No significant dyspeptic effects or reduction in edoxaban absorption are observed with concomitant use of proton pump inhibitors. Approximately $50 \%$ of edoxaban is excreted by the kidneys, and its half-life is $9-11 \mathrm{~h}$. There is minimal interaction with drugs that are metabolized by (hepatic) cytochrome CYP3A4, and less than $4 \%$ of edoxaban is eliminated by the liver. ${ }^{(18)}$

In 2013, a study called the Hokusai-VTE trial was published. ${ }^{(25)}$ Unlike the literature trend for factor Xa antagonists, the authors chose to test the drug only in the extended period of the treatment of VTE and not in the initial phase. Therefore, 4,921 patients with DVT and 3,319 patients with PTE were randomized, after being treated with either unfractionated heparin or enoxaparin for at least 5 days, to receive either edoxaban $(60 \mathrm{mg} /$ day or $30 \mathrm{mg} /$ day in patients with a body weight $<60 \mathrm{~kg}$ or a creatinine clearance of 30-50 $\mathrm{mL} / \mathrm{min}$ ) or warfarin, for a period ranging from 3 to 12 months. Edoxaban was as effective as warfarin for the prevention of VTE recurrence (recurrence rate: $3.2 \%$ in the edoxaban group vs. $3.5 \%$ in the warfarin group; $p<0.001$ for non-inferiority). Edoxaban was superior to warfarin for clinically relevant bleeding ( $8.5 \%$ vs. $10.3 \% ; p=0.004)$ and similar with regard to major bleeding (1.4\% vs. $1.6 \% ; 95 \% \mathrm{CI}: 0.59-1.21)$. A peculiarity of the Hokusai-VTE trial was the inclusion of a greater number of patients with PTE and some evidence of right ventricular dysfunction (as assessed by measurement of $\mathrm{N}$-terminal pro-brain natriuretic peptide levels and CT measurement of right ventricular dimensions); therefore, those patients were potentially more severely ill. Among those 938 patients, the use of edoxaban resulted in a lower rate of VTE recurrence than did the use of warfarin (3.3\% vs. $6.2 \%$; RR $=$ 0.52; 95\% CI: 0.28-0.98). ${ }^{(25)}$

The Hokusai-VTE study ${ }^{(25)}$ proved to be quite robust in acute VTE, showing that edoxaban is not inferior to warfarin, with it possibly being superior to warfarin for patients with PTE and right ventricular dysfunction and potentially being beneficial in terms of bleeding. However, despite the convenient dosing schedule (once daily), the study design does not allow for the use of edoxaban as a single drug, and its administration should be preceded by at least 5 days of some type of intravenous or subcutaneous anticoagulation.

The recommended dose of edoxaban is the same as that used in the Hokusai-VTE study ${ }^{(25)}: 60 \mathrm{mg} /$ day. In patients with a body weight $<60 \mathrm{~kg}$ or a creatinine clearance of $15-50 \mathrm{~mL} / \mathrm{min}$, a dose of $30 \mathrm{mg} /$ day is recommended. The dosing schedule is also convenient in this case, and this can influence patient adherence to treatment, improving its results. The limitation that 
edoxaban cannot be used in the initial treatment of VTE should be emphasized.

\section{SPECIAL SITUATIONS FOR USE OF THE NEW ANTICOAGULANTS}

\section{Renal failure and advanced age}

Chronic renal failure is a well-known risk factor for the development of VTE as well as for bleeding, with or without anticoagulant therapy. ${ }^{(26)}$ Likewise, age is a known risk factor for the development of VTE. The risk of VTE is known to be 4 to 6 times higher in patients > 70 years of age and to double every decade of life. ${ }^{(27,28)}$ In addition, age alone is a determinant of outcome in pulmonary embolism, with the risk of death from a thromboembolic event being 2.3 times higher in patients $>75$ years of age than in the younger population. ${ }^{(29)}$ However, elderly patients and patients with renal failure are both at an increased risk of bleeding while taking anticoagulants. ${ }^{(30,31)}$ In addition, patients who are elderly or have renal failure tend to have a larger number of comorbidities, which makes it difficult to manage the anticoagulant therapy.

Elderly patients and patients with renal failure were both analyzed in the aforementioned large-scale studies of new anticoagulants. ${ }^{(19-25)}$ A recent meta-analysis ${ }^{(32)}$ evaluated these subgroups of patients and showed that the new anticoagulants have a better safety and efficacy profile in elderly patients, as well as having a safety and efficacy profile comparable to that of the conventional treatment in patients with renal failure. In fact, this so-called fragile population (those who are elderly and/or have renal failure and/or are at extreme levels of body weight) is the population that most benefits from the use of the new drugs, whether in terms of efficacy or, especially, in terms of safety.

\section{Cancer}

Cancer patients are at an increased risk both for thromboembolic events in general and for disease manifestations of greater severity. ${ }^{(33)}$ Approximately $10-20 \%$ of VTE patients have a history of or have active cancer. $^{(34)}$ In contrast, cancer patients are at a 4- to 7-times higher risk of developing VTE. ${ }^{(35)}$ The likelihood of thromboembolic events of greater severity is also associated with the presence of cancer.

Cancer patients have been included in all of the randomized studies on the use of new anticoagulants and VTE, and the results in favor of the new drugs persisted in the subgroup analyses. However, the therapies were not compared with the currently recommended gold standard, but rather with warfarin. According to the ACCP, the current therapy of choice for patients with cancer-related VTE is based on the use of low-molecular-weight heparins. ${ }^{(9)}$ That recommendation is based on studies showing the efficacy of this type of treatment in the maintenance phase of VTE treatment in the cancer population, when compared with that of warfarin. ${ }^{(36)}$ There has been no direct comparison between the new anticoagulants and low-molecular-weight heparins, in terms of their effects in the medium term, for VTE treatment in cancer patients. Such studies are in progress and, until their results are available, the new anticoagulants should still be used with caution in this population, it being preferable that low-molecular-weight heparins be used.

\section{MANAGEMENT OF COMPLICATIONS OF VTE TREATMENT WITH THE NEW ANTICOAGULANTS}

\section{Bleeding}

A major concern of inexperienced physicians with regard to the new anticoagulants is management of bleeding, especially major bleeding. The fear of this complication with regard to prescribing warfarin has been mitigated by 50 years of experience and clinical practice. In fact, hemorrhagic complications should be borne in mind by anyone prescribing an anticoagulant medication. In this case, prevention is essential; some simple measures can reduce an individual's patient risk of bleeding, regardless of the selected anticoagulant. Avoiding concomitant use of nonsteroidal anti-inflammatory drugs or antiplatelet agents, controlling systemic blood pressure, assessing the need for prophylaxis of upper gastrointestinal tract bleeding with the use of a proton pump inhibitor, assessing renal and hepatic function periodically, and educating patients are measures that contribute to the prevention of such complications.

Serum activity levels of the new anticoagulants cannot be accurately monitored with current coagulation tests. Even for factor Xa antagonists, anti-factor Xa test results do not have a linear correlation with anticoagulant activity, because they are calibrated to measure activity of low-molecular-weight heparins.

In addition to prevention, data from recent registries are quite reassuring with regard to the bleeding rates with the new anticoagulants ${ }^{(37)}$ : rates of major bleeding reach 3-4 per 100 patients per year, with a mortality rate of $6 \%$ in these cases. The same registries show a rate of severe bleeding of 8 per 100 patients per year, with a mortality rate of $15 \%$ with the use of warfarin. ${ }^{(38)}$ Another peculiarity of the use of the new anticoagulants is that the pattern of hemorrhagic complications seems to be different from that usually found with the use of warfarin. With the new anticoagulants, hemorrhages tend to be more common in the digestive tract, the approach to which is less complex than is that required when hemorrhage affects the central nervous system (more common with the use of warfarin). ${ }^{(39)}$

The management of bleeding with the use of the new anticoagulants is similar to the management of warfarin-related hemorrhages ${ }^{(40)}$ : in the event of minor local bleeding, it is suggested that the following dose be discontinued and that mechanical compression or local measures, such as nasal packing for a nosebleed, be used. In the event of major hemorrhage, in addition 
to local measures and clinical support measures (such as fluid replacement, red blood cell transfusion, and platelet transfusion if platelet count is below 60,000), administration of prothrombin complex (25-50 U/ $\mathrm{kg}$ ) or activated prothrombin complex (50-200 U/kg) can be considered. Prothrombin complex has high levels of vitamin K-dependent coagulation factor. Therefore, because it antagonizes the action of warfarin, prothrombin complex can also antagonize the action of the new anticoagulants, given that its formulation contains a large amount of factor II (for dabigatran) or factor X (for rivaroxaban, apixaban, and edoxaban). Therefore, in theory, for the treatment of potentially fatal hemorrhage in patients receiving one of the new anticoagulants, the use of prothrombin complex is preferred over the traditional use of fresh frozen plasma. In plasma, the blocked factors (II or X) are diluted among all other serum proteins, therefore being present in smaller amounts and consequently less effective. However, the validity of this strategy has not been systematically evaluated, having been investigated only in experimental models. ${ }^{(41)}$ Likewise, one can consider administering activated factor VII (at a dose of $90 \mu \mathrm{g} / \mathrm{kg}$ ), which, when given at high doses such as the one suggested, is able to induce propagation of the coagulation cascade, even if this cascade is blocked at some point below, whether in factor II or factor X. If the drug in question is dabigatran, another alternative can be hemodialysis, given that dabigatran can thus be removed.

Recently, antidotes for dabigatran-idarucizumab ${ }^{(42)}$ and for factor Xa antagonists - andexanet alfa( ${ }^{(43)}$ - have become available. Neither antidote has been widely used. It is likely that they will not become widely available and that they will rarely actually be required. However, the existence of these antidotes should encourage the use of the new anticoagulants and reduce the level of concern on the part of the medical community regarding the management of bleeding.

Another situation that may raise questions is perioperative management when the patient is taking one of the drugs in this new class. For elective surgery, it will suffice to consider the half-life of the drugs and discontinue their use for a period of not less than $24 \mathrm{~h}$. For emergency surgery in patients who haven taken a new anticoagulant within a period less than that of its half-life, the use of the aforementioned antidotes (idarucizumab for dabigatran or andexanet alfa for factor Xa antagonists) can be considered for acute reversal of anticoagulation so that the surgical procedure can be performed with increased safety. The timing of the reinitiation of anticoagulant therapy should be individualized on the basis of the potential postoperative risk of hemorrhage as well as the risk of another thromboembolic event, which is increased postoperatively. It is recommended that the new anticoagulants be restarted as early as possible. If, for surgical reasons, fasting is required, one can consider the use of low-molecular-weight heparins for a transitional period until re-establishment of proper gastrointestinal transit and reinitiation of the new anticoagulants. ${ }^{(18)}$

\section{Recurrence}

As previously mentioned, even if the new anticoagulants are used appropriately, there may be recurrence of VTE, especially in the acute phase but also in the long-term and extended periods. In such cases, the ACCP recommendation is that, in addition to confirming that it truly is a new episode of VTE and checking patient adherence to treatment (remembering that, given the shorter half-life of the drugs, missing even a single dose is sufficient to leave patients susceptible to a new event), the drug being used be temporarily replaced with a low-molecular-weight heparin for at least 30 days. ${ }^{(9)}$

\section{CURRENT RECOMMENDATION FOR VTE TREATMENT}

On the basis of the aforementioned studies, phase IV studies, and large epidemiologic registries that confirmed the data from phase III studies in real life, ${ }^{(44,45)}$ the most recent guidelines of the European Society of Cardiology/European Respiratory Society assign treatment with the new anticoagulants the same grade of recommendation and level of evidence as those assigned to the conventional treatment of heparins followed by warfarin, without hierarchization. ${ }^{(46)}$ However, in the most recent ACCP guidelines, the new anticoagulants, mainly because of their favorable safety profile, are placed as the first choice for the treatment of VTE unrelated to cancer. ${ }^{(9)}$ This emphasizes the relevance of this class of drugs and the need for knowledge of their pharmacological properties and side effect profiles. Safety in prescribing the new drugs, as well as confidence in managing their complications, especially hemorrhagic complications, will come with the experience of using them and with clinical practice.

\section{REFERENCES}

1. Heit JA. The epidemiology of venous thromboembolism in the community. Arterioscler Thromb Vasc Biol. 2008;28(3):370-2. http:// dx.doi.org/10.1161/ATVBAHA.108.162545

2. Cohen AT, Agnelli G, Anderson FA, Arcelus JI, Bergqvist D, Brecht $\mathrm{JG}$, et al. Venous thromboembolism (VTE) in Europe. The number of VTE events and associated morbidity and mortality. Thromb Haemost. 2007;98(4):756-64. http://dx.doi.org/10.1160/th07-03-0212

3. Andrade Ede O, Bindá FA, Silva AM, Costa TD, Fernandes MC, Fernandes MC. Risk factors and prophylaxis for venous thromboembolism in hospitals in the city of Manaus, Brazil. J Bras
Pneumol. 2009:35(2):114-21.

4. Biss TT, Brandão LR, Kahr WH, Chan AK, Williams S. Clinical features and outcome of pulmonary embolism in children. $\mathrm{Br} J$ Haematol. 2008;142(5):808-18. http://dx.doi.org/10.1111/j.13652141.2008.07243.x

5. Konstantinides S, Torbicki A. Management of venous thromboembolism: an update. Eur Heart J. 2014;35(41):2855-63. http:// dx.doi.org/10.1093/eurheartj/ehu243

6. Kernohan RJ, Todd C. Heparin therapy in thromboembolic disease. Lancet. 1966;1(7438):621-3. http://dx.doi.org/10.1016/S0140- 


\section{6(66)90822-1}

7. BARRITT DW, JORDAN SC. Anticoagulant drugs in the treatment of pulmonary embolism. A controlled trial. Lancet. 1960;1(7138):130912.

8. Hull R, Delmore T, Genton E, Hirsh J, Gent M, Sackett D, et al. Warfarin sodium versus low-dose heparin in the long-term treatment of venous thrombosis. N Engl J Med. 1979;301(16):855-8. http:// dx.doi.org/10.1056/NEJM197910183011602

9. Kearon C, Akl EA, Ornelas J, Blaivas A, Jimenez D, Bounameaux $\mathrm{H}$, et al. Antithrombotic Therapy for VTE Disease: CHEST Guideline and Expert Panel Report. Chest. 2016;149(2):315-52. http://dx.doi. org/10.1016/j.chest.2015.11.026

10. Hull R, Delmore T, Carter C, Hirsh J, Genton E, Gent M, et al. Adjusted subcutaneous heparin versus warfarin sodium in the long-term treatment of venous thrombosis. N Engl J Med. 1982;306(4):189-94. http://dx.doi.org/10.1056/NEJM198201283060401

11. Ridker PM, Goldhaber SZ, Danielson E, Rosenberg Y, Eby CS, Deitcher SR, et al. Long-term, low-intensity warfarin therapy for the prevention of recurrent venous thromboembolism. N Engl J Med. 2003;348(15):1425-34. http://dx.doi.org/10.1056/NEJMoa035029

12. Hutten BA, Prins MH. Duration of treatment with vitamin $\mathrm{K}$ antagonists in symptomatic venous thromboembolism. Cochrane Database Syst Rev. 2006;(1):CD001367. http://dx.doi org/10.1002/14651858.cd001367.pub2

13. Phillips KW, Ansell J. The clinical implications of new ora anticoagulants: will the potential advantages be achieved? Thromb Haemost. 2010;103(1):34-9. http://dx.doi.org/10.1160/TH09-06-0361

14. Kakkar AK, Mueller I, Bassand JP, Fitzmaurice DA, Goldhaber SZ, Goto $S$, et al. Risk profiles and antithrombotic treatment of patients newly diagnosed with atrial fibrillation at risk of stroke: perspectives from the international, observational, prospective GARFIELD registry. PloS One. 2013;8(5):e63479. http://dx.doi.org/10.1371/ journal.pone.0063479

15. Connolly SJ, Ezekowitz MD, Yusuf S, Eikelboom J, Oldgren J, Parekh A, et al. Dabigatran versus warfarin in patients with atrial fibrillation. N Engl J Med. 2009;361(12):1139-51. http://dx.doi.org/10.1056/ NEJMoa0905561

16. Holbrook AM, Pereira JA, Labiris R, McDonald H, Douketis JD, Crowther $\mathrm{M}$, et al. Systematic overview of warfarin and its drug and food interactions. Arch Intern Med. 2005;165(10):1095-106. http:// dx.doi.org/10.1001/archinte.165.10.1095

17. Amin A, Deitelzweig S, Jing Y, Makenbaeva D, Wiederkehr D, Lin $J$, et al. Estimation of the impact of warfarin's time-in-therapeutic range on stroke and major bleeding rates and its influence on the medical cost avoidance associated with novel oral anticoagulant uselearnings from ARISTOTLE, ROCKET-AF, and RE-LY trials. J Thromb Thrombolysis. 2014;38(2):150-9. http://dx.doi.org/10.1007/s11239013-1048-z

18. Heidbuchel H, Verhamme P, Alings M, Antz M, Hacke W, Oldgren J, et al. EHRA practical guide on the use of new oral anticoagulants in patients with non-valvular atrial fibrillation: executive summary. Eur Heart J. 2013;34(27):2094-106. http://dx.doi.org/10.1093/eurheartj/ eht134

19. Schulman S, Kearon C, Kakkar AK, Mismetti P, Schellong S, Eriksson $\mathrm{H}$, et al. Dabigatran versus warfarin in the treatment of acute venous thromboembolism. N Engl J Med. 2009;361(24):2342-52. http:// dx.doi.org/10.1056/NEJMoa0906598

20. Schulman S, Kearon C, Kakkar AK, Schellong S, Eriksson H, Baanstra $D$, et al. Extended use of dabigatran, warfarin, or placebo in venous thromboembolism. N Engl J Med. 2013;368(8):709-18. http://dx.doi. org/10.1056/NEJMoa1113697

21. EINSTEIN Investigators $E$, Bauersachs R, Berkowitz SD, Brenner $B$, Buller HR, Decousus $H$, et al. Oral rivaroxaban for symptomatic venous thromboembolism. N Engl J Med. 2010;363(26):2499-510. http://dx.doi.org/10.1056/NEJMoa1007903

22. EINSTEIN-PE Investigators, Büller HR, Prins $M H$, Lensin AW, Decousus $H$, Jacobson $B F$, et al. Oral rivaroxaban for the treatment of symptomatic pulmonary embolism. N Engl J Med. 2012;366(14):1287-97. http://dx.doi.org/10.1056/NEJMoa1113572

23. Agnelli G, Buller HR, Cohen A, Curto M, Gallus AS, Johnson M, et al. Oral apixaban for the treatment of acute venous thromboembolism. N Engl J Med. 2013;369(9):799-808. http://dx.doi.org/10.1056/ NEJMoa1302507

24. Agnelli G, Buller HR, Cohen A, Curto M, Gallus AS, Johnson M, et al. Apixaban for extended treatment of venous thromboembolism. N Engl J Med. 2013;368(8):699-708. http://dx.doi.org/10.1056/

\section{NEJMoa1207541}

25. Hokusai-VTE Investigators, Büller HR, Décousus $H$, Grosso MA Mercuri M, Middeldorp S, et al. Edoxaban versus warfarin for the treatment of symptomatic venous thromboembolism. N Engl J Med. 2013;369(15):1406-15. http://dx.doi.org/10.1056/NEJMoa1306638

26. Ocak G, Lijfering WM, Verduijn M, Dekker FW, Rosendaal FR, Cannegieter SC, et al. Risk of venous thrombosis in patients with chronic kidney disease: identification of high-risk groups. J Thromb Haemost. 2013;11(4):627-33. http://dx.doi.org/10.1111/ith.12141

27. Anderson FA Jr, Wheeler HB, Goldberg RJ, Hosmer DW, Patwardhan NA, Jovanovic $B$, et al. A population-based perspective of the hospital incidence and case-fatality rates of deep vein thrombosis and pulmonary embolism. The Worcester DVT Study. Arch Intern Med. 1991;151(5):933-8. http://dx.doi.org/10.1001/ archinte.1991.00400050081016

28. Stein PD, Hull RD, Kayali F, Ghali WA, Alshab AK, Olson RE. Venous thromboembolism according to age: the impact of an aging population. Arch Intern Med. 2004:164(20):2260-5. http://dx.doi. org/10.1001/archinte.164.20.2260

29. Laporte S, Mismetti P, Décousus H, Uresandi F, Otero R, Lobo J et al. Clinical predictors for fatal pulmonary embolism in 15,520 patients with venous thromboembolism: findings from the Registro Informatizado de la Enfermedad TromboEmbolica venosa (RIETE) Registry. Circulation. 2008;117(13):1711-6. http://dx.doi.org/10.1161/ CIRCULATIONAHA.107.726232

30. Nieto JA, Solano R, Ruiz-Ribó MD, Ruiz-Gimenez N, Prandoni P Kearon $\mathrm{C}$, et al. Fatal bleeding in patients receiving anticoagulant therapy for venous thromboembolism: findings from the RIETE registry. J Thromb Haemost. 2010;8(6):1216-22. http://dx.doi. org/10.1111/j.1538-7836.2010.03852.x

31. Prandoni P, Trujillo-Santos J, Sanchez-Cantalejo E, Dalla Valle $F$, Piovella $\mathrm{C}$, Pesavento $\mathrm{R}$, et al. Major bleeding as a predictor of mortality in patients with venous thromboembolism: findings from the RIETE Registry. J Thromb Haemost. 2010;8(11):2575-7. http:// dx.doi.org/10.1111/.1538-7836.2010.04039.x

32. Geldhof V, Vandenbriele C, Verhamme P, Vanassche T. Venous thromboembolism in the elderly: efficacy and safety of nonVKA oral anticoagulants. Thromb J. 2014;12:21. http://dx.doi. org/10.1186/1477-9560-12-21

33. Marinho FC, Takagaki TY. Hypercoagulability and lung cancer. $J$ Bras Pneumol. 2008;34(5):312-22. http://dx.doi.org/10.1590/S180637132008000500011

34. Büller HR, Davidson BL, Decousus H, Gallus A, Gent M, Piovella $F$, et al. Fondaparinux or enoxaparin for the initial treatment of symptomatic deep venous thrombosis: a randomized trial. Ann Intern Med. 2004;140(11):867-73. http://dx.doi.org/10.7326/00034819-140-11-200406010-00007

35. Blom JW, Doggen CJ, Osanto S, Rosendaal FR. Malignancies, prothrombotic mutations, and the risk of venous thrombosis. JAMA 2005;293(6):715-22. http://dx.doi.org/10.1001/jama.293.6.715

36. Lee AY, Levine MN, Baker RI, Bowden C, Kakkar AK, Prins M et al. Low-molecular-weight heparin versus a coumarin for the prevention of recurrent venous thromboembolism in patients with cancer. N Engl J Med. 2003;349(2):146-53. http://dx.doi.org/10.1056/ NEJMoa025313

37. Majeed A, Hwang HG, Connolly SJ, Eikelboom JW, Ezekowitz $M D$, Wallentin $L$, et al. Management and outcomes of major bleeding during treatment with dabigatran or warfarin Circulation. 2013;128(21):2325-32. http://dx.doi.org/10.1161/ CIRCULATIONAHA.113.002332

38. Beyer-Westendorf J, Förster K, Pannach S, Ebertz F, Gelbricht $V$, Thieme $C$, et al. Rates, management, and outcome of rivaroxaban bleeding in daily care: results from the Dresden NOAC registry. Blood. 2014;124(6):955-62. http://dx.doi.org/10.1182/ blood-2014-03-563577

39. Chan NC, Paikin JS, Hirsh J, Lauw MN, Eikelboom JW, Ginsberg JS. New oral anticoagulants for stroke prevention in atrial fibrillation: impact of study design, double counting and unexpected findings on interpretation of study results and conclusions. Thromb Haemost. 2014;111(5):798-807. http://dx.doi.org/10.1160/TH13-11-0918

40. Siegal DM, Crowther MA. Acute management of bleeding in patients on novel oral anticoagulants. Eur Heart J. 2013;34(7):489498b. http://dx.doi.org/10.1093/eurheartj/ehs408

41. Lazo-Langner A, Lang ES, Douketis J. Clinical review: Clinical management of new oral anticoagulants: a structured review with emphasis on the reversal of bleeding complications. Crit Care 2013;17(3):230. http://dx.doi.org/10.1186/cc12592 
42. Pollack CV Jr, Reilly PA, Eikelboom J, Glund S, Verhamme P, Bernstein RA, et al. Idarucizumab for Dabigatran Reversal. N Engl J Med. 2015;373(6):511-20. http://dx.doi.org/10.1056/NEJMoa1502000

43. Siegal DM, Curnutte JT, Connolly SJ, Lu G, Conley PB, Wiens BL, et al. Andexanet Alfa for the Reversal of Factor Xa Inhibitor Activity. N Engl J Med. 2015;373(25):2413-24. http://dx.doi.org/10.1056/ NEJMoa1510991

44. Schulman S, Kakkar AK, Goldhaber SZ, Schellong S, Eriksson $H$, Mismetti $P$, et al. Treatment of acute venous thromboembolism with dabigatran or warfarin and pooled analysis. Circulation. 2014;129(7):764-72. http://dx.doi.org/10.1161/ CIRCULATIONAHA.113.004450

45. Ageno W, Mantovani LG, Haas S, Kreutz R, Monje D, Schneider J, et al. Safety and effectiveness of oral rivaroxaban versus standard anticoagulation for the treatment of symptomatic deep-vein thrombosis (XALIA): an international, prospective, non-interventional study. Lancet Haematol. 2016;3(1):e12-21. http://dx.doi.org/10.1016/ S2352-3026(15)00257-4

46. Konstantinides SV, Torbicki A, Agnelli G, Danchin N, Fitzmaurice D Galie N, et al. 2014 ESC guidelines on the diagnosis and management of acute pulmonary embolism. Eur Heart J. 2014;35(43):3033-69 3069a-3069k.

47. Schulman S, Kakkar AK, Goldhaber SZ, Schellong S, Eriksson $H$, Mismetti $P$, et al. Treatment of acute venous thromboembolism with dabigatran or warfarin and pooled analysis Circulation. 2014;129(7):764-72. http://dx.doi.org/ 10.1161/ CIRCULATIONAHA.113.004450 